\title{
Wearable cooling system to manage heat in protective clothing
}

\author{
Gunatilake Banda Delumburewatte ${ }^{1}$ and Tilak Dias ${ }^{2}$ \\ ${ }^{1}$ Department of Textile and Apparel Technology, The Open University of Sri Lanka, Sri Lanka \\ ${ }^{2}$ School of Art and Design, Nottingham Trent University, UK
}

\section{Key words}

Protective clothing, heat management, Micro cooling, peltiers, CBRN clothing, metabolic heat,

\begin{abstract}
This paper presents the working principle of a wearable miniature cooling system investigated by us for managing heat and sweat effectively and efficiently under extreme conditions. The cooling system consists of peltier units and mini refrigerant channels incorporated in a knitted spacer structure. The knitted spacer structure absorbs sweat and accumulates it to keep the skin dry. The cold side of the peltier units absorbs heat from the skin and transfer the heat to the refrigerant, which is converted to a gas by the absorption of evaporative heat. The mini refrigerant channels are connected to a high pressure liquid refrigerant cylinder and to a gas receiver via polymer tubes. The wearable cooling system was evaluated by using a test rig designed to simulate the origination of human body heat and a sealed environment similar to that inside a CBRN garment. Test results show that the temperature remains constant, when the cooling system is active even though the heat energy was produced continuously. This wearable cooling system can be used to manage heat and sweat under extreme conditions.
\end{abstract}

\section{Introduction}

In the case of normal clothing, the sweat absorbency and removal via evaporation provides a major source of cooling to the body and reduce heat stress. However, protective clothing is far less permeable to heat and vapour than normal clothing. The sweat evaporation is not possible for an entirely enclosed protective clothing environment such as CBRN (Chemical, Biological, Radiological or Nuclear) and fire-fighter garment systems. As such it is important to remove sweat from the skin to maintain tactile and sensorial comfort while wearing protective clothing.

\subsection{Literature review}

Many studies on Cooling Garments (CG) with regard to physiological and medical effects have been carried out since the first such study by the Royal Aircraft Establishment (UK) in 1964 [3]. However, three different types of cooling garments, with tubing carrying either cool air, cool water, or a refrigerant, inside the garments, have been tested on humans during the last four to five decades. Portable cooling systems have relied upon one of the following techniques, phase-change materials, adsorption, absorption or vapour compression.

In 1972 Shvartz [5] compared different cooling units and recommended that the percentage of tubing in the cooling garment for maximum effectiveness should be: Torso: $30 \%$, Head and neck: $25 \%$, Thighs: $17 \%$, Upper arms: 15\%, Calves:8\%, and Forearms: 5\%. 
In 2004 Pourmohamadian et al. [24] conducted research using flexible polyamide tubing $0.2 \mathrm{~mm}$ in diameter instead of metallic tubing, passing direct cooling gas, R-134a. Very lightweight tubing was capable of handling pressure up to $2.07 \mathrm{MPa}$ (300psi) and was compatible with R-134a.

In 2006, Flouris and Cheung, [11] studied microclimate liquid cooling systems and noted that currently available flexible tubing is thermally insulating and provides limited thermal absorption from the skin. It is further stated that fitted garment during both static and dynamic work is critical to optimal heat exchange and need computerized manufacturing in order to optimize fitting to the individual.

Relatively even tubing distribution over the body surface does not change the regional variations in both heat exchange capacity and thermo sensitivity. Further research is required to address regions with high thermal sensitivity such as the face and the neck. Exploiting region- and conditions- specific thermoregulatory variations by altering either tubing or cooling distribution will enhance efficiency and thermal comfort in a variety of environments and conditions.

The integration of an automatic cooling control would both enhance the efficiency of the thermal suit and also remove unnecessary monitoring by the wearer. More research is required in order to develop an optimum and, if possible, prescient automatic control design for LQMCS.

Theoretical calculation by the authors show that the $1.1 \mathrm{grams} / \mathrm{s}$ flow rate of liquid refrigerant (R134) is sufficient to manage total of 220w heat energy, which is generated by a person under extreme conditions. The flow rate can be $0.1375 \mathrm{~g} / \mathrm{s}$ in a channel, if the cooling garment contains 8 equally distributed channels. The volume of refrigerant in a channel will depend on the enthalpy, the temperature, the pressure and the wetness of the refrigerant, which vary throughout the channel.

\section{Methods and Apparatus}

\subsection{Development of mini heat exchangers}

Basic to any cooling system with liquid refrigerant is the absorption of heat energy while the liquid transforms to vapour by increasing the enthalpy of the refrigerant. The efficiency of the cooling system is mostly dependent on the heat transfer between the refrigerant and the body of the system. If the heat transfer is inadequate, then the conversion from liquid to vapour will be not completed and the refrigerant will remain as wet gas. Therefore a good heat exchanger is important to complete the process of converting liquid to superheated vapour with higher enthalpy to absorb more heat.

\subsubsection{Concept}

In order to increase the efficiency of the heat exchanging process a design has been conceived that combines a thermoelectric cooler with a copper box, in which the liquid refrigerant converts to vapour by absorbing heat energy. Commercially available Thermo Electric module (peltier) units can be fitted into copper boxes as forcible heat exchangers. Figure 1 shows a photo and a line diagram of a proposed mini heat exchanger unit assembly with copper box and thermoelectric module, which are pasted together using thermal grease to produce good heat transfer. 

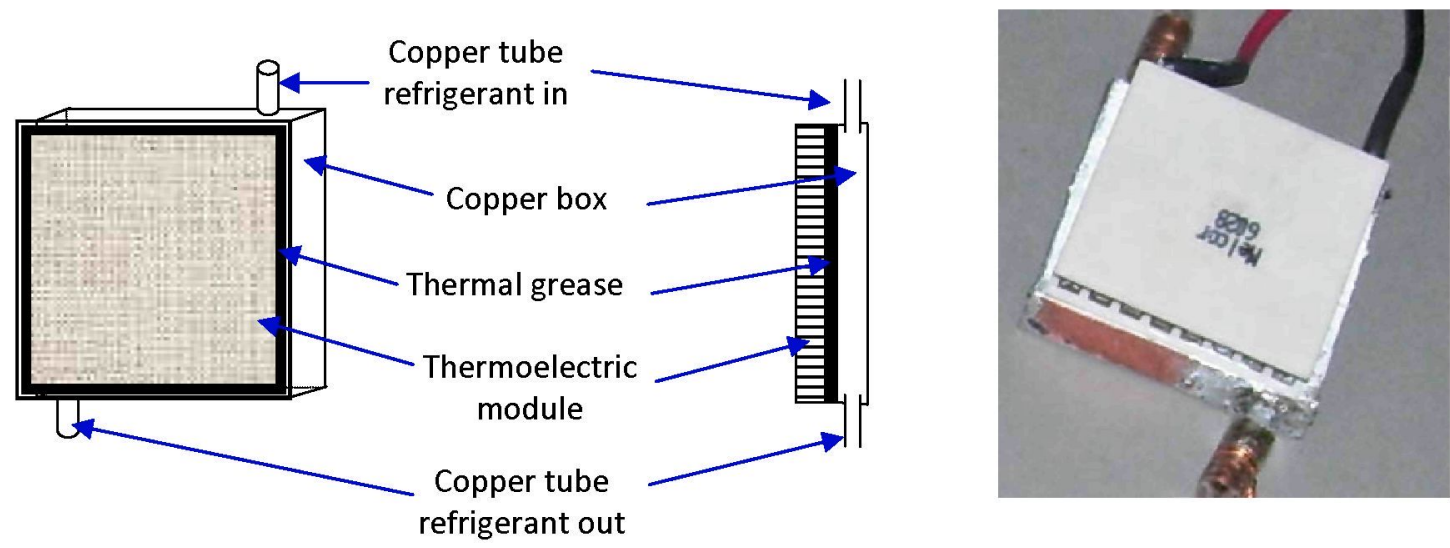

Figure1: Mini heat exchanger unit with copper box and thermoelectric module

Figure 2 shows a schematic of the refrigerant channel with four of the mini heat exchanger units that have been joined serially together with polymeric tubes to pass the refrigerant from the pressurised can to the distal end.

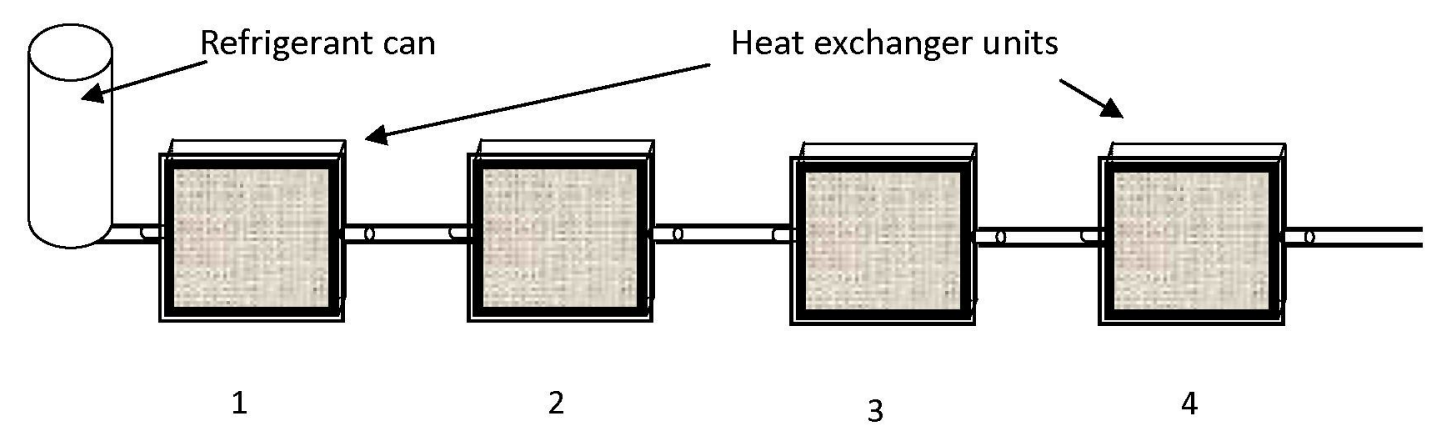

Figure 2: Line diagram of four mini heat exchangers connected with polymeric tubes.

Copper boxes and the thermoelectric coolers are arranged in such a way that the refrigerant from the can enters the first copper box as liquid and leaves from the fourth copper box as super heated vapour. The mini heat exchanger units are connected with fine polymer tubes for the purpose of refrigerant flow. The copper boxes functioned as heat exchangers between refrigerant and the thermoelectric module. Each box is made out of thin, $0.35 \mathrm{~mm}$ copper sheet and has approximate dimensions of $5 \times 25 \times 25 \mathrm{~mm}$. However, theoretical and experimental work has to be carried out to estimate the specification of the unit, the quantity of refrigerant flow in the channel and the diameter of the polymeric tubes used to interconnect the copper boxes. The inner diameter of the exit at the inlet side copper tubes has been changed after calculating the pore area to work as throttle, which also creates the required pressure drop.

Commercially available polymeric tubes are used in the experiment and they are compatible with R134a refrigerant, suitable for the temperature range from -43 to $+74{ }^{\circ} \mathrm{C}$ and a working pressure of 4.8 bar. The inner diameter of the tube is $1.6 \mathrm{~mm}$ and the outer diameter is $4.8 \mathrm{~mm}$.

A commercially available thermoelectric module was connected to a DC power supply to work as heat exchanger between the copper box and the simulated skin. The thermoelectric module is connected to the copper box in such a way that the side attached to the copper box will release heat energy, which is absorbed by the refrigerant to increase the enthalpy 
by converting the liquid to vapour. The other side of the module will absorb heat energy from the skin or skin environment.

\subsection{Experimental setup for heat transfer and temperature measurement}

The mini heat exchangers developed as shown in Figure 1 were inserted into the pockets of a weft knitted spacer fabric and connected together with nylon tubes, as explained previously, to make the cooling unit. The fabric with the cooling unit was placed on a copper sheet with a heat mat, and the assembly was then inserted into a pouch made out of fabric used in Chemical Biological Radiation and Nuclear (CBRN) suits. Figure 3 to Figure 6 explain the steps followed in developing the test rig to evaluate the effectiveness of the cooling units. Figure 3a shows the assembly of mini heat exchanger units before insertion into the spacer fabric. Figure $3 \mathrm{~b}$ shows the mini heat exchanger units connected to the refrigerant can, a pressure gauge and a flow meter.

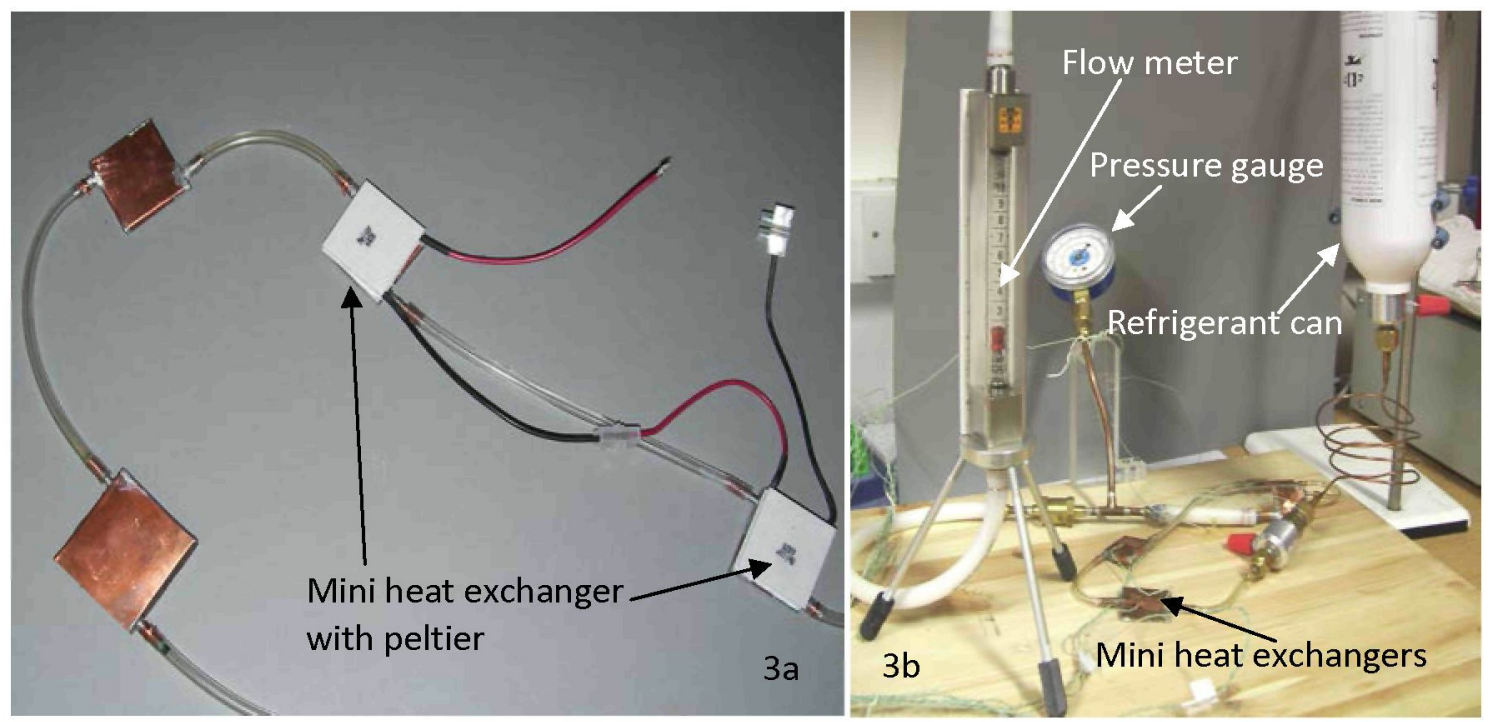

Figure 3: Cooling assembly with accessories

Figure 4 shows the simulated skin copper sheet by the side of the cooling layer with the heat exchangers, the cooling layer in an upside down position and the inner single layer of the weft knitted spacer fabric is cut to show the heat exchangers. The copper sheet is curved into the shape of the trunk of a human body and fixed to a wooden board. A heat mat is pasted to the underside of the copper sheet for the purpose of providing heat, and thermocouples are placed on the copper sheet to monitor the temperatures. 


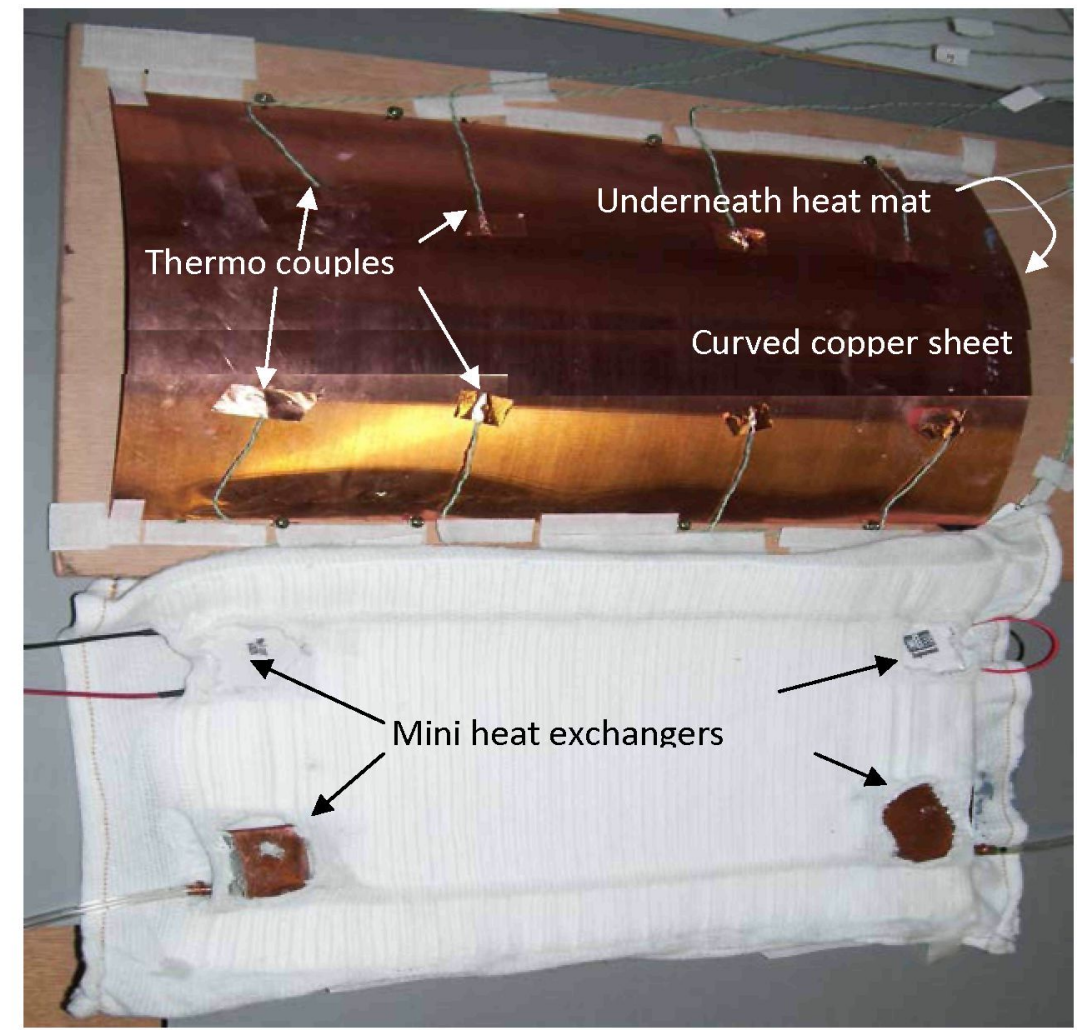

Figure 4: Spacer fabric after inserting mini heat exchangers and copper sheet

Figure 5 shows the spacer fabric with the cooling system after folding on to the copper sheet. Then the cooling system may be connected to the refrigerant can and the flow meter via a pressure gauge as shown in Figure 6.

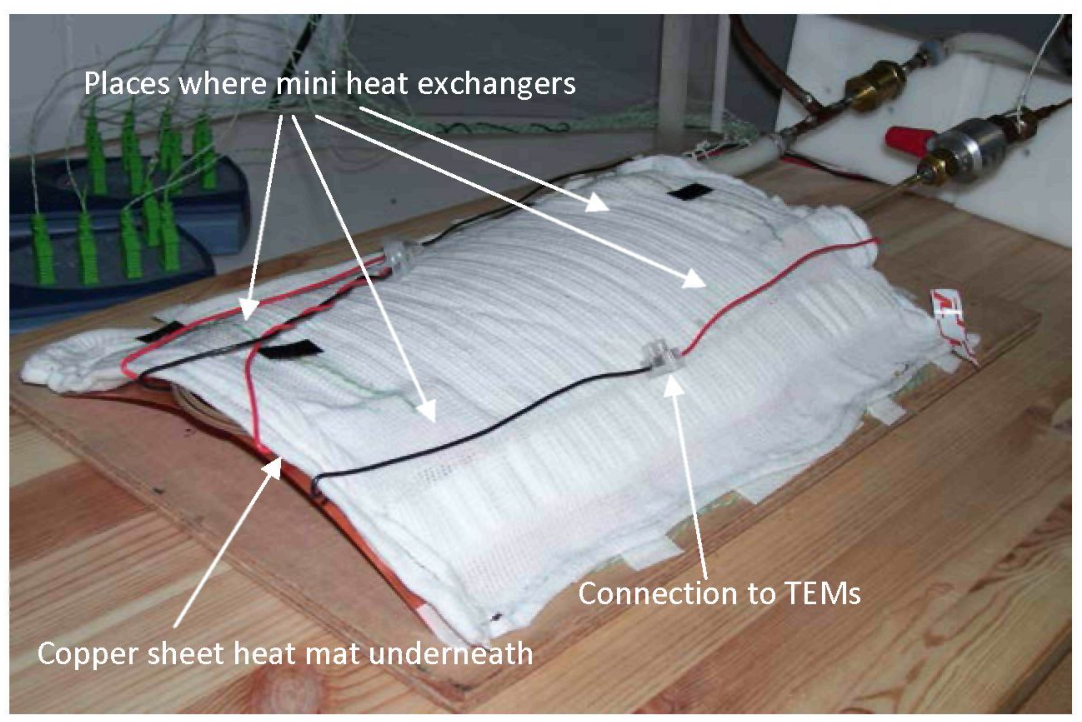

Figure 5: Spacer fabric after inserting mini heat exchangers on copper sheet 


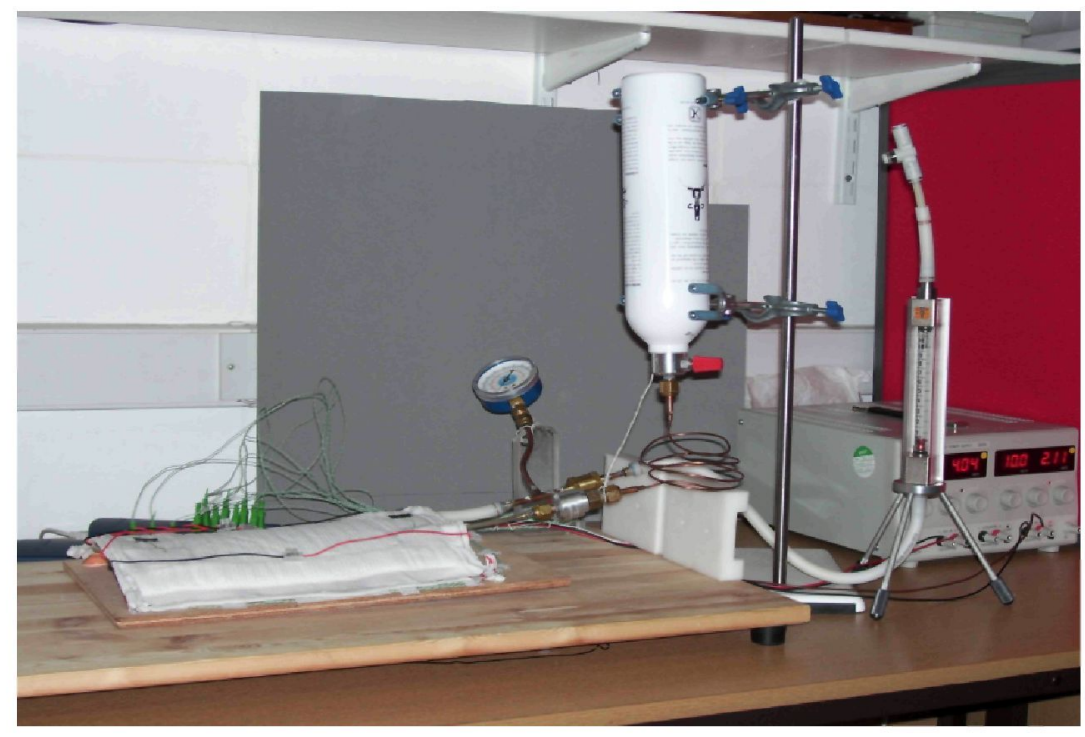

Figure 6: Cooling assembly with refrigerant can, pressure gauge and flow meter

The whole assembly, consisting of the wooden board, the copper sheet with heat mat, and the spacer fabric with the mini heat exchangers, is inserted into a CBRN pouch as shown in Figure $7 \mathrm{~b}$. Figure $7 \mathrm{a}$ shows how the cooling system is inserted into the CBRN pouch.
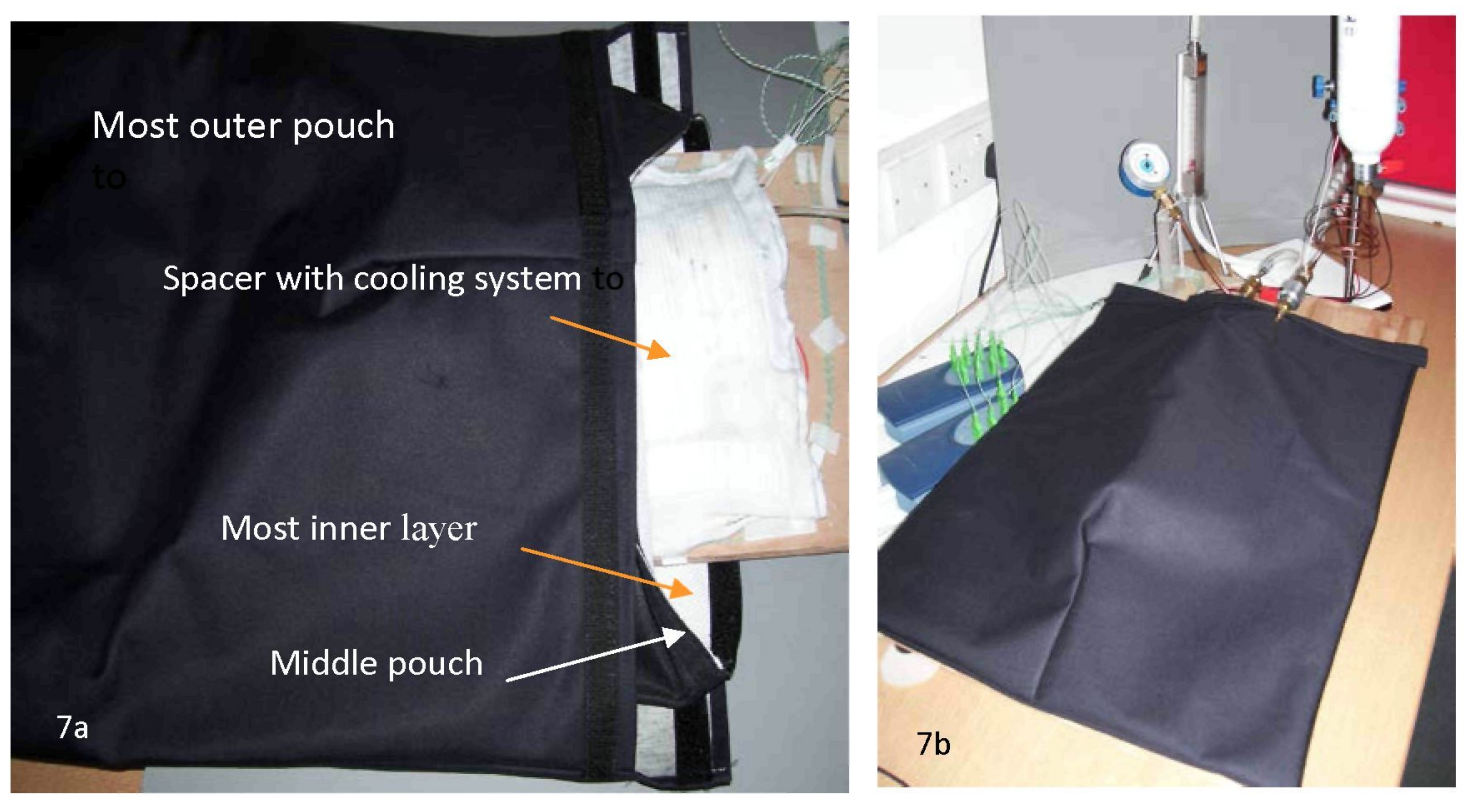

Figure 7 Cooling assembly and CBRN pouch

The CBRN pouch consists of two pouches, the outer pouch is made out of chemical protective over garment material. The second pouch is made from two fabrics; the outer fabric is a fabric with an active carbon layer to protect against exposure to radioactive and nuclear material. The inner fabric of the second pouch is made to protect the active carbon layer from rubbing on the inner materials and the fabric is stitched to the second pouch.

The effectiveness of the cooling unit was tested using the test rig explained above. Temperature variation on the copper sheet has been observed and recorded with the variation of power supply to the TEMs and the refrigerant flow through the channel. Five different types of tests were carried out to estimate the efficiency of the cooling system. The first two tests were carried out to monitor the increase of the temperatures inside the 
pouch with $15 \mathrm{~W}$ and $20 \mathrm{~W}$ heating but without cooling for about 20 minutes of time. Third and fourth tests were carried out to estimate the required refrigerant and power supply to TEMs, for cooling to maintain the temperatures inside the pouch, when the heater is on under dry fabric condition. A fifth test was carried out to monitor the effectiveness of the cooling system under wet fabric conditions.

\section{Results and discussion}

Graph shows the temperature regulation with a cooling channel consisting of mini heat exchangers on simulated skin while production of heat energy similar to a person under extreme condition.

The results of the first two tests carried out to observe the heat build up inside the CBRN pouch under heating of $20 \mathrm{~W}$ and $15 \mathrm{~W}$ are shown in Figure 8. Figure 8.a shows the increase of temperature inside the CBRN pouch, when the heat mat produces heat energy of $20 \mathrm{~W}$. The temperature shown in the graph, Temp.1 is the average temperature on the copper sheet about $5 \mathrm{~cm}$ away from the mini heat exchangers; it increases by about $30^{\circ} \mathrm{C}$ within 10 minutes. Temp. 2 is the average temperature on the copper sheet under the mini heat exchangers and increases by about $24^{\circ} \mathrm{C}$ within 10 minutes. Temp. 3 shows the average surrounding temperature inside the CBRN pouch which increases by about $14^{\circ} \mathrm{C}$ within 10 minutes. Figure 8.b shows similar behaviour of the temperature increase when the heat mat produces $15 \mathrm{~W}$ of heat energy continuously. However, the temperatures increase at Temp.1 by about $28^{\circ} \mathrm{C}$, at Temp. 2 by $30^{\circ} \mathrm{C}$ and at Temp. 3 by about $20^{\circ} \mathrm{C}$ within 20 minutes.

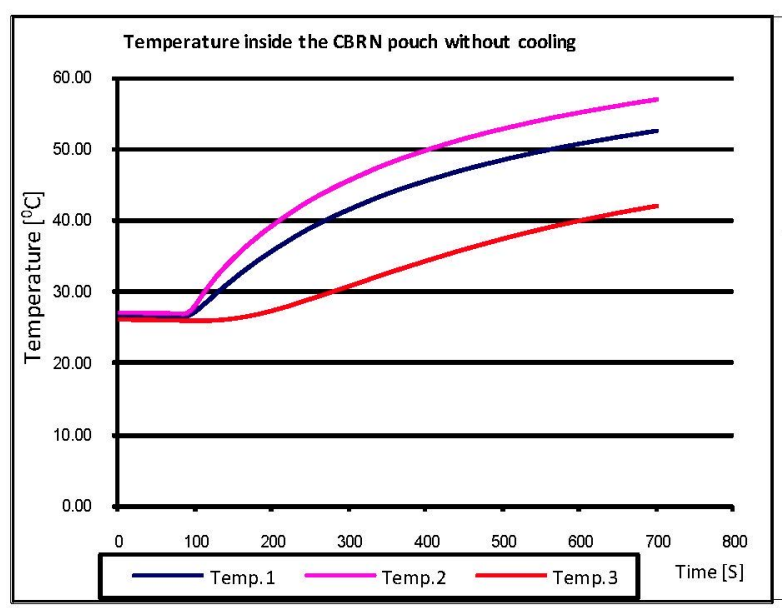

a. 20 Watt heat generation

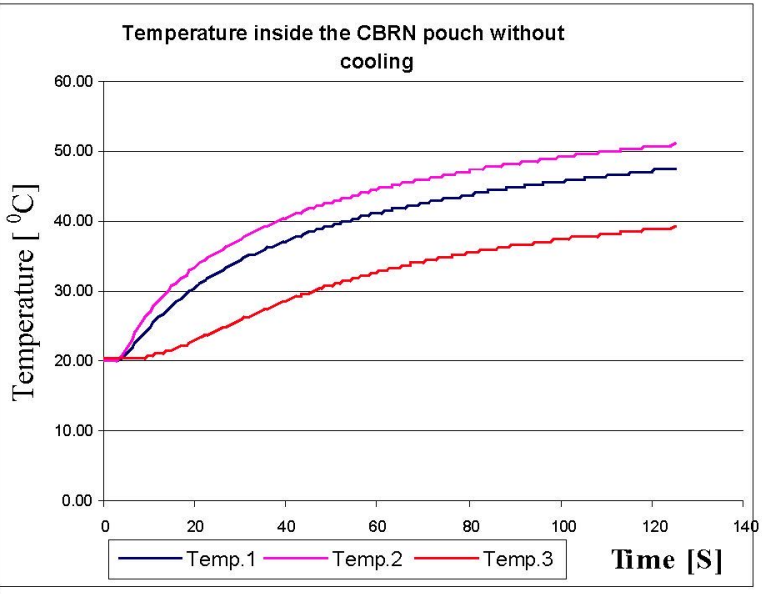

b. 15 Watt heat generation

Figure 8 Temperature increase inside the CBRN pouch without cooling

The $3^{\text {rd }}$ test with the cooling system in the CBRN pouch was carried out with a similar set up but with little variation in refrigerant flow rate $(850 \mathrm{cc} / \mathrm{min}-875 \mathrm{cc} / \mathrm{min})$, power supply $(2.5 \mathrm{~A}$ $3.1 \mathrm{~A})$, and heating capacity (15W) over a period of 68 minutes.

Figure 9 shows the temperature variation during $3^{\text {rd }}$ test due to the variation of power supply to the thermo electric coolers (TEMs) and refrigerant flow. An attempt was made to maintain the refrigerant flow at around $850 \mathrm{cc} / \mathrm{min}$ and retain minimum variation in temperatures during the test. However, with the changes of power supply to the TEMs, the temperatures on the surfaces of the TEMs result in changes in flow rate. All these contribute to quick changes in temperatures of the exit vapour. It is noticeable that the 
temperatures are stable between 3200 and 3900 s (between 53 and 65 minutes). In this time interval, the refrigerant flow is about $850 \mathrm{cc} / \mathrm{min}$, heating is about $15 \mathrm{~W}$ and power supply to the TEMs is $3 \mathrm{~V}$ and $3 \mathrm{~A}$. Forced heat pumped by the hot side of the TEMs, is absorbed by the refrigerant to increase the enthalpy and the temperature. The cold side of the TEMs, absorb heat energy from the surroundings to provide cooling.

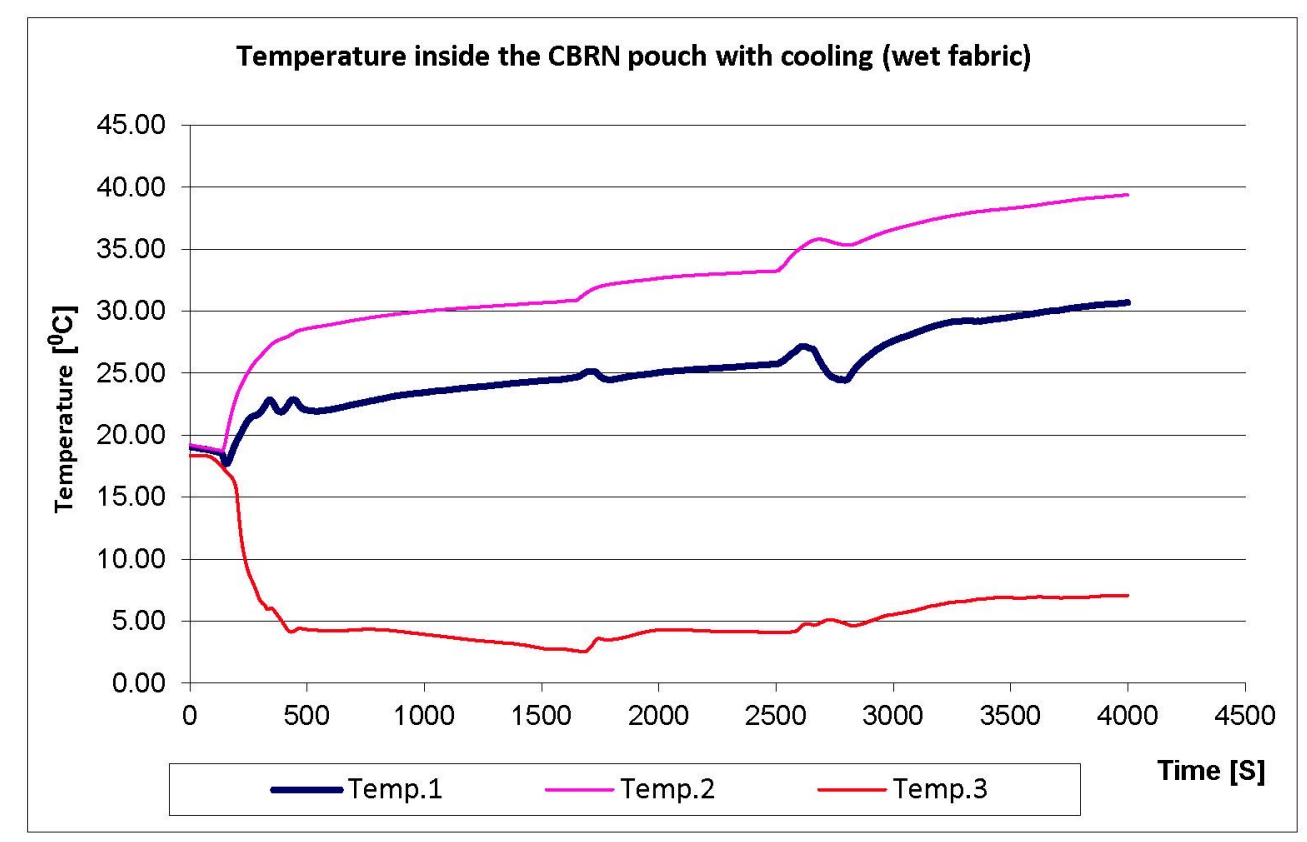

Temp. 1 is the temperature between skin and the peltiers

Figure 9 Temperature increase inside the CBRN pouch with cooling (dry Fabric)

The $4^{\text {th }}$ test with the cooling system in the CBRN pouch was carried out to test the cooling behaviour under wet condition with variation in flow rate, power supply, and heating capacity over a period of 66 minutes. The fabric was wetted and allowed to drip out for one hour before the test for testing the effectiveness of the cooling system after sweating. The refrigerant flow $(700 \mathrm{cc} / \mathrm{min}-850 \mathrm{cc} / \mathrm{min})$, heating power $(15 \mathrm{~W}-21 \mathrm{~W})$ and the power supply to the mini heat exchangers $(2.5 \mathrm{~V}$ and $3.0 \mathrm{~A})$ are varies

Figure 10 show the temperature variations with the cooling system inside the CBRN pouch under wet fabric conditions, when the heat mat produces $15 \mathrm{~W}, 18 \mathrm{~W}$ and $21 \mathrm{~W}$ heat energy over a period of $25 \mathrm{~min}, 15 \mathrm{~min}$ and $25 \mathrm{~min}$ respectively. Curve denotations are the same as in Figure 9 and the power supply to the TEMs is about 3.0A.

The first part of the graph up to $25 \mathrm{~min}$, shows that the average temperature is maintained below $31^{\circ} \mathrm{C}$ within the pouch with heating of $15 \mathrm{~W}$ and a refrigerant flow of about 800 $\mathrm{cc} / \mathrm{min}$. The second part of the graph, $25 \mathrm{~min}$ to $40 \mathrm{~min}$ shows that the average temperature is maintained below $33^{\circ} \mathrm{C}$ within the pouch under heating of $18 \mathrm{~W}$ and a refrigerant flow of about $850 \mathrm{cc} / \mathrm{min}$. 


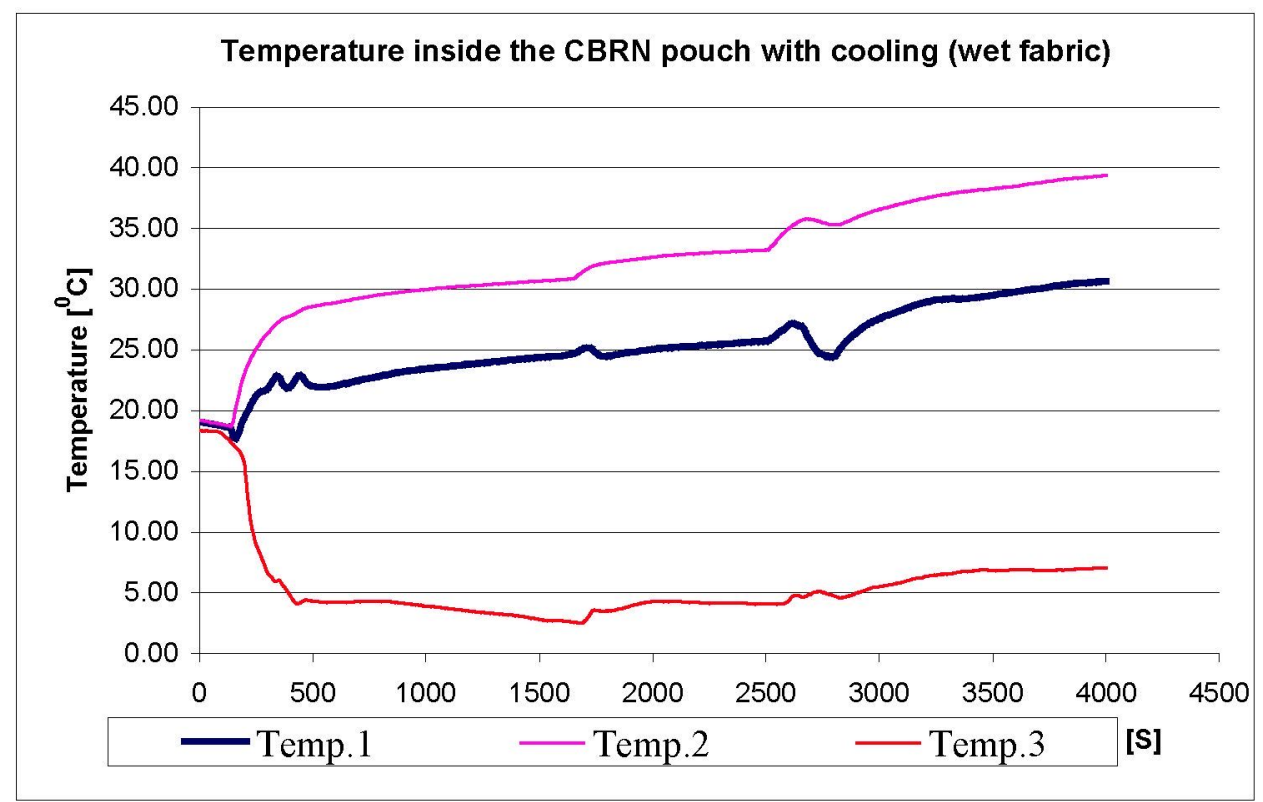

Temp. 1 is the temperature between skin and the peltiers

Figure 10 Temperature increase inside the CBRN pouch with cooling (wet fabric)

The third part of the graph, from $40^{\circ} \mathrm{C}$ to $65^{\circ} \mathrm{C}$ shows that an average temperature is maintained below $40^{\circ} \mathrm{C}$ within the pouch with heating of $21 \mathrm{~W}$ and a refrigerant flow of about $900 \mathrm{cc} / \mathrm{min}$. The temperature of exit vapour reaches $25^{\circ} \mathrm{C}$. However, it is very low at the beginning due to sudden increase of the refrigerant flow. It is very important to note that the sudden increase of refrigerant flow causes a flow of the refrigerant with low enthalpy resulting in the refrigerant flow with low temperatures. This test results show that cooling under wet fabric condition due to sweating is more effective than that cooling under dry condition.

\section{Conclusions}

The mini heat exchangers consisting of copper boxes and thermoelectric modules, connected with nylon tubes to make the cooling channels can provide almost equal low temperatures at all surfaces next to the skin.

Running the test rig for about 65 minutes showed that the amount of refrigerant flow required to maintain lower temperatures varied with the heating, but it is about $850 \mathrm{cc} / \mathrm{min}$ for $15 \mathrm{~W}$. On some occasions, the TEMs are not properly pumping heat and show saturation. It is suggested that the power supply must be adjusted accurately and suitable thermoelectric modules must be selected or custom - made to work continually as heat exchangers, depending on the amount of heat to be pumped. The throttle area at the exit to individual boxes and the dimensions of the copper boxes must be also evaluated accurately to maintain the temperature of the refrigerant in the boxes considering the pressure drop. Experimental investigation under a CBRN environment enables the conclusion to be drawn that a cooling system with mini heat exchangers could be used effectively to produce cooling for the wearer of the appropriate knitted spacer clothing in challenging conditions. 


\section{References}

1. Johnson, R.W., Criteria for thermal regulation for manned spacecraft cabin, in Nasa Technical note TN D-3349, L.R. Center, Editor. 1966.

2. Shvartz, E., Efficiency and effectiveness of different water cooled suits. a review, Aerospace Medicine, 1972. 43: p. 488 - 491.

3. Pourmohamadian, N., M.L. Philpott and M.A. Shannon. Novel connection for nonmetallic, flexible, thin, Microchannel heat exchangers. in Proceding of the second International Conference on Microchannels and minichannels, (ICMM2004). 2004. Rochester, NY, United States: American Society of Mechanical Engineers, New Yourk, NY 10016-5990, United states.

4. Flouris, A.D., Cheung, S. S. , Design and Control Optimization of Microclimate Liquid Cooling Systems Underneath Protective Clothing. Annals of Biomedical Engineering, 2006. 34(3): p. 359-372.

5. Delkumburewatte, G.B., 2008, The development of a cooling system in a knitted structure to manage heat and moisture under extreme conditions, $\mathrm{PhD}$ thesis submitted to school of material, The University of Manchester. 